\title{
PASTEJO ROTACIONADO EM BRACHIARIA BRIZANTHA CV. MARANDU PARA MELHORIA DA PRODUÇÃO LEITEIRA
}

\section{ARTIGO ORIGINAL}

SOARES, Marcio Groto ${ }^{1}$, CAMARGO, Simone Cristina², FRASSETTO, Matheus Orlandin ${ }^{3}, \mathrm{ABREU}$, Hélio Mar de ${ }^{4}$

SOARES, Marcio Groto. Et al. Pastejo rotacionado em Brachiaria brizantha cv. marandu para melhoria da produção leiteira. Revista Científica Multidisciplinar Núcleo do Conhecimento. Ano. 06, Ed. 09, Vol. 07, pp. 104-118. Setembro 2021. ISSN: 2448-0959, Link de acesso:

https://www.nucleodoconhecimento.com.br/veterinaria/brachiaria-brizantha, DOI: 10.32749/nucleodoconhecimento.com.br/veterinaria/brachiaria-brizantha

\section{RESUMO}

Em propriedades leiteiras, para que haja um aumento do lucro, é necessário aumentar a eficiência dos fatores de produção principalmente a nutrição que impacta no custo fixo. Cada vez mais, busca-se um equilíbrio entre o fornecimento de ração e de pasto. O método de pastejo rotacionado vem sendo adotado por vários produtores, por ter uma boa produtividade em uma área menor. Contudo, as pastagens utilizadas nesse tipo de pastejo, apesar de apresentarem excelente qualidade, possuem maior exigência nutricional. Objetivou-se com esse trabalho, realizar a análise econômica do custo de produção de leite, mediante a implantação de pastejo rotacionado, e troca de pasto nativo para pastagem de Brachiaria brizantha $\mathrm{cv}$. marandu, em uma propriedade de agricultura familiar. Este trabalho foi elaborado na cidade de Foz do Iguaçu. Utilizou-se uma área de $6300 \mathrm{~m}^{2}$ divididos em 28 piquetes de $225 \mathrm{~m}^{2}$ utilizando cerca elétrica. O custo total de produção foi de $R \$$

\footnotetext{
${ }^{1}$ Graduação.

2 Doutorado.

${ }^{3}$ Mestre.

${ }^{4}$ Graduação.
}

$\mathrm{RC}: 98111$

Disponível em: https://www.nucleodoconhecimento.com.br/veterinaria/brachiariabrizantha 
6,047.40 tendo uma margem positiva de $R \$ 5,143.61$ anual. De acordo com os resultados obtidos nas análises econômicas, conclui-se que a implantação do pastejo rotacionado e realização da troca da pastagem nativa pela Brachiaria brizantha cv. Marandu, é um manejo viável, uma vez que as receitas geradas pela venda do leite, foram suficientes para cobrir os custos totais de produção.

Palavras-chave: Custo, Leite, Forragem, Piquete, Manejo.

\section{INTRODUÇÃO}

O Brasil ocupa a quarta posição no ranking mundial de produção de leite. No ano de 2018, a região Sul foi responsável por 34\% da produção total do país (ANUÁRIO LEITE, 2019). Só o estado do Paraná nesse ano produziu em média 4,37 bilhões de litros de leite, dos quais o oeste paranaense foi responsável por 19\% (IBGE, 2018).

A bovinocultura leiteira no estado do Paraná, é uma atividade típica da agricultura familiar, representando aproximadamente $85,1 \%$ dos produtores do estado (SEAB, 2018). A maioria desses produtores utiliza a pastagem como principal fonte de alimento para os animais. A área média ocupada com pastagens no estado é de 16,6 hectares (IPARDES, 2009).

Embora o Brasil se destaque na produção de leite, sua produtividade fica em torno de 1,689 L/vaca/ano, sendo este valor inferior aos dos Estados Unidos, China, Rússia, Argentina, União Europeia e Nova Zelândia, que produzem mais de 3 L/vaca/ano. Um dos fatores responsáveis pela baixa produtividade de leite, é o uso de gramíneas pouco produtivas e de baixa qualidade nutricional, em conjunto com a manejo inadequado, tanto dos animais como das pastagens (GONÇALVES et al., 2003).

Uma maneira de intensificar a produção animal em sistemas de pastejo é à adoção de forragens melhoradas, mais adaptadas ao clima, com maior potencial de produção e de melhor qualidade (JANK, 2017). Entre as diversas forragens existentes no Brasil, destaca-se a variedade híbrida do capim Brachiaria brizantha

RC: 98111

Disponível em: https://www.nucleodoconhecimento.com.br/veterinaria/brachiariabrizantha 
cv. marandu, por apresenta um bom valor nutritivo e alta produção de biomassa, adaptando-se bem a solos de média e boa fertilidade, sendo tolerante à acidez do solo (FONSECA et al., 2010).

O manejo correto da pastagem, deve ser outro ponto a ser observado nas propriedades de bovino de leite. Um dos pastejo que vêm se demonstrando viável, é o rotacionado, onde há subdivisão da pastagem em três ou mais piquetes. Este tipo de pastejo apresenta diversas vantagens, como: maior uniformidade de pastejo, maior aproveitamento das forrageiras, maior taxa de lotação, e maior longevidade de capins que formam touceiras (FUKUMOTO et al., 2010).

Diferentes pesquisas vêm demonstrando bons resultados para bovinocultura leiteira, com a implantação do pastejo rotacionado em gramínea Brachiaria brizantha cv. marandu (GONÇALVES, 2003); (DEMSKI, 2013), (MOURA, 2017). De acordo com (ANDRADE, 2008), esse tipo de pastagem não tolera pastejo contínuo.

Com a correta escolha da forrageira, manejo adequado e melhor utilização da área da propriedade, busca-se gerar economia ao produtor, uma vez que diminuirá o custo de produção. De acordo com (GERON, 2012), o custo de produção é a soma de todos os valores gastos com insumos e operações e serviços utilizados no processo produtivo de certa atividade. Com o estudo dos custos, é possível verificar como os recursos empregados em um processo de produção estão sendo remunerados e como está a rentabilidade da atividade (GERON et al., 2014).

Desta maneira, objetivou-se com esse trabalho, realizar a análise econômica do custo de produção de leite, mediante a implantação de pastejo rotacionado, e troca de pasto nativo para pastagem de Brachiaria brizantha cv. marandu, em uma propriedade de agricultura familiar.

\section{MATERIAL E MÉTODOS}

O experimento foi realizado em uma propriedade leiteira situada na cidade de Foz do Iguaçu - PR, Latitude: -25.5469, Longitude: $-54.588225^{\circ} 32^{\prime} 49^{\prime \prime}$ Sul, $54^{\circ} 35^{\prime} 18^{\prime \prime}$

RC: 98111

Disponível em: https://www.nucleodoconhecimento.com.br/veterinaria/brachiariabrizantha 
Oeste. Esta propriedade é composta por uma área de 5,0 hectares, nesta área era desenvolvido uma pecuária leiteira tradicional à região, onde os animais tinham acesso a toda área de pastejo, composta por capim nativo de baixa produtividade, não havia disponibilidade de sal mineral, apenas sal comum no cocho e sendo apenas disponibilizada uma suplementação na hora da ordenha de $10 \mathrm{~kg}$ de por animais em lactação e o acesso a água era de um riacho que passa pela propriedade.

A propriedade apresenta seis bovinos de raça leiteira, composto por quatro vacas adulta, sendo duas vacas em lactação e duas vacas secas, mais duas novilhas. Estes animais eram manejados em toda área de pastagem durante todo o ano e os animais lactantes recebiam $10 \mathrm{~kg}$ de ração industrializada por dia.

Iniciou-se o trabalho com uma visita na propriedade, para um diagnóstico. Foi realizado as medições da área de pastagem com o uso do GPS (Figura 1) e também a coleta de solo (Figura 2). Os resultados da análise de solo encontram-se a (Tabela 1). 
Figura 1 - Foto satélite da área experimental, com a demarcação da área de pastagem:

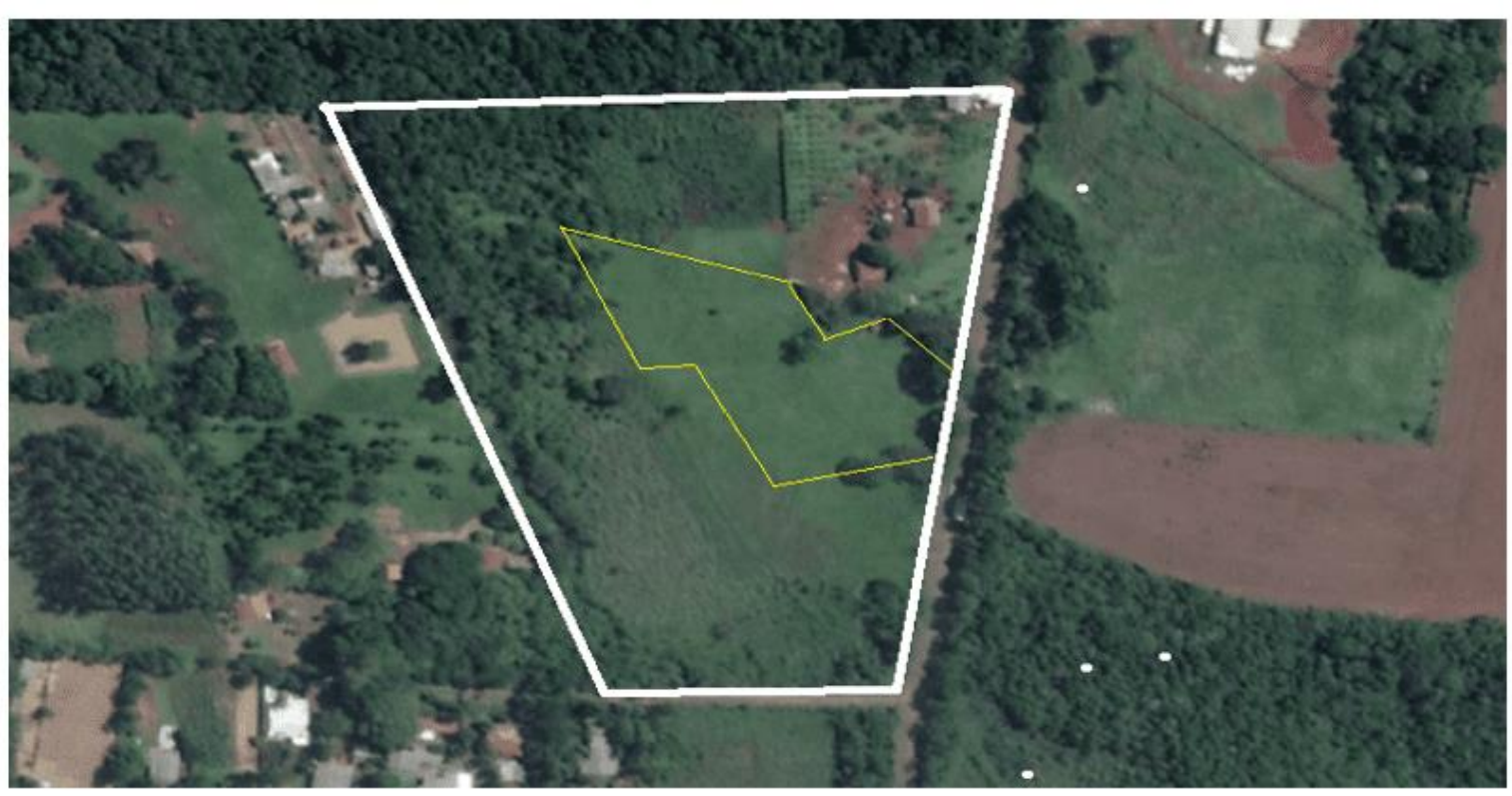

Fonte: Google Earth.

RC: 98111

Disponível em: https://www.nucleodoconhecimento.com.br/veterinaria/brachiariabrizantha 
Figura 2 - Coleta de amostra do solo:

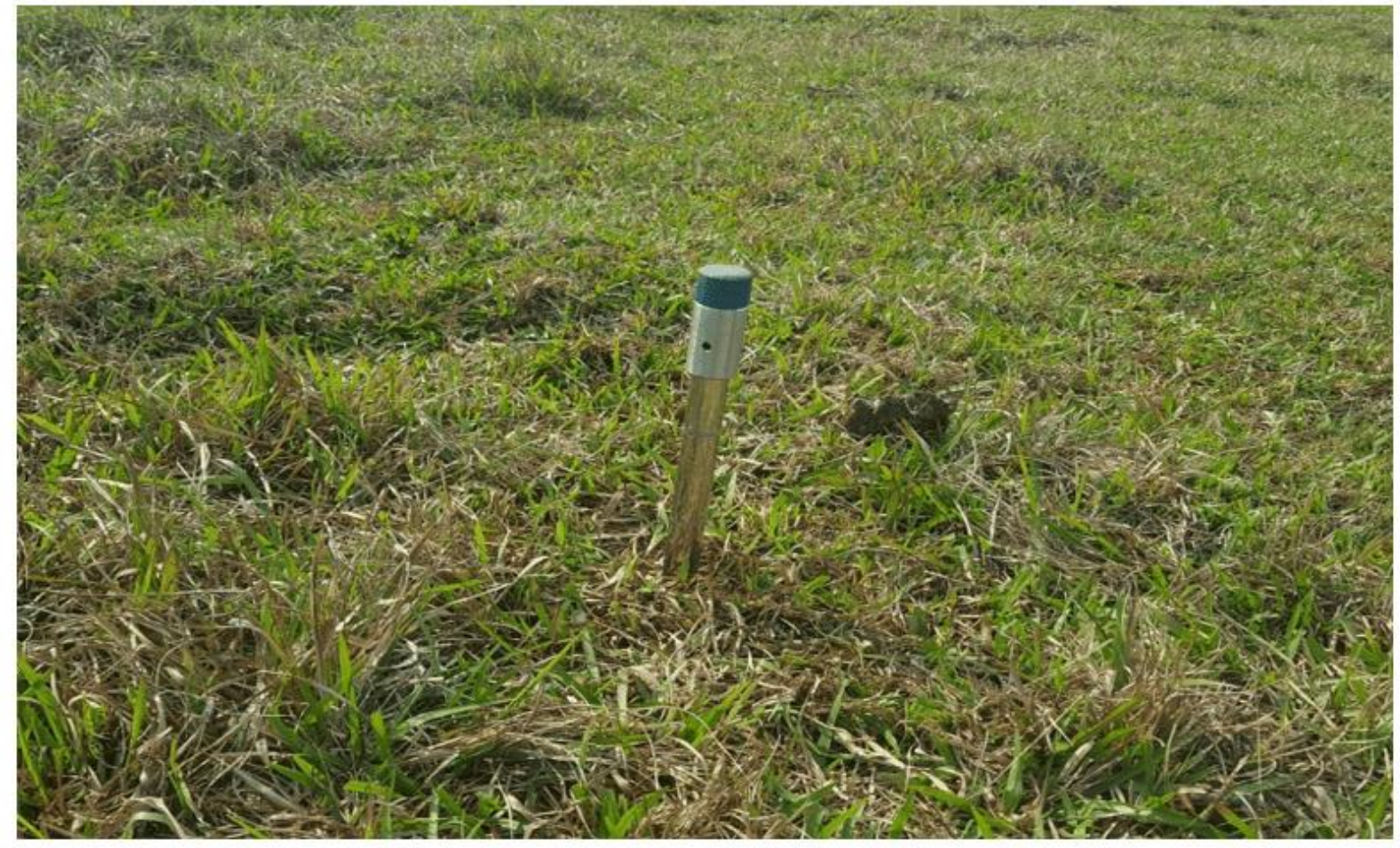

Fonte: Arquivo Pessoal.

Tabela 1 - Resultados da análise de solo da área experimental:

\begin{tabular}{|c|c|c|c|c|c|c|c|c|c|c|c|c|c|c|}
\hline $\mathrm{pH}$ & & & $\mathrm{K}$ & $\mathrm{Ca}$ & $\mathrm{Mg}$ & Al & $\mathrm{H}+\mathrm{Al}$ & CTC & SB & V & $\mathrm{m}$ & $\mathrm{Ca}$ & $\mathrm{Mg}$ & $\mathrm{K}$ \\
\hline \multirow[t]{2}{*}{$\mathrm{CaCl} 2$} & M.O & $\mathrm{P}$ (res) & & & & & & & & & & & & \\
\hline & $\mathrm{g} / \mathrm{Kg}$ & $\mathrm{mg} / \mathrm{dm} 3$ & \multicolumn{5}{|c|}{$\mathrm{mmol} / \mathrm{dm} 3$} & $\%$ & & & \multicolumn{4}{|c|}{ \% СТC } \\
\hline 5,2 & 38 & 14 & 3 & 21 & 5 & 2,7 & 29 & 58 & 29 & 50 & 8 & 36 & 9 & 5 \\
\hline
\end{tabular}

Fonte: FZEA/USP.

Após o recebimento da análise de solo foram feitos os cálculos de correção do solo, onde o V\% era de 58\%. Para correção do $\mathrm{pH}$ do solo, foi necessário $800 \mathrm{~kg} \mathrm{ha}^{-1} \mathrm{de}$ calcário dolomítico com PRNT de $86 \%$. Para correção do fosforo foi necessário a adição de $250 \mathrm{~kg} \mathrm{ha}^{-1}$ do fertilizante superfosfato simples. Para a adubação de produção, foi utilizado $250 \mathrm{~kg} \mathrm{ha}^{-1}$ de ureia agrícola (FRASSETO, 2015).

RC: 98111

Disponível em: https://www.nucleodoconhecimento.com.br/veterinaria/brachiariabrizantha 
Para dar início ao preparo do solo, realizou-se a aplicação do calcário a lanço, em toda a área experimental, e logo após, utilizou-se grade pesada, com uma profundidade de $40 \mathrm{~cm}$, que serviu para incorporação do calcário ao solo, quebra de compactações superficiais e dar condições ao crescimento da nova espécie forrageira.

Para um dimensionamento da área necessária para pastejo, as vacas foram pesadas através de uma fita de pesagem com 95\% de acuracidade, totalizando $1.950 \mathrm{~kg}$ ou 4,5 UA. Pelo fato de ser utilizado bovinos leiteiros, foi determinado que os animais teriam acesso a um piquete novo, ao final de um dia de pastejo. Assim sendo, utilizou-se dados de (FRASSETO 2015), em que uma UA (450 kg de peso vivo), necessitam de pelo menos $50 \mathrm{~m}^{2}$ por dia de área de pastejo. Sabendo que haviam 4,5 UA, a área de cada piquete foi de $225 \mathrm{~m}^{2}$. Foram construídos um total de 28 piquetes, utilizando-se 0,63 hectare. Durante a construção dos piquetes, foi necessário adicionar três corredores, com $2 \mathrm{~m}$ de largura.

Para a divisão dos piquetes foram utilizados 50 mourões, 72 vergalhões de $10 \mathrm{~mm}$, 32 vergalhões de $12 \mathrm{~mm}, 500 \mathrm{~m}$ de arame tri galvanizado para cerca o perímetro total da área e $2500 \mathrm{~m}$ de fio eletroplástico para a divisão interna dos piquetes, 150 isoladores tipo castanha, 22 isoladores gancho e 114 isoladores tipo vergalhão. Foi utilizado fio de arame com altura de $80 \mathrm{~cm}$ em relação ao solo e cada $10 \mathrm{~m}$ implantou-se uma barra de vergalhão de $1,5 \mathrm{~m}$ com isolador para que mantivesse a altura em relação ao solo, também foi utilizado fio eletroplástico, para divisão dos piquetes e redução dos custos de formação. Para eletrificar os arames, foi utilizado um eletrificador da marca Sentinela modelo 30.000, como mínimo de 5000 volts.

RC: 98111

Disponível em: https://www.nucleodoconhecimento.com.br/veterinaria/brachiariabrizantha 
Figura 3 - Croqui da divisão dos piquetes:

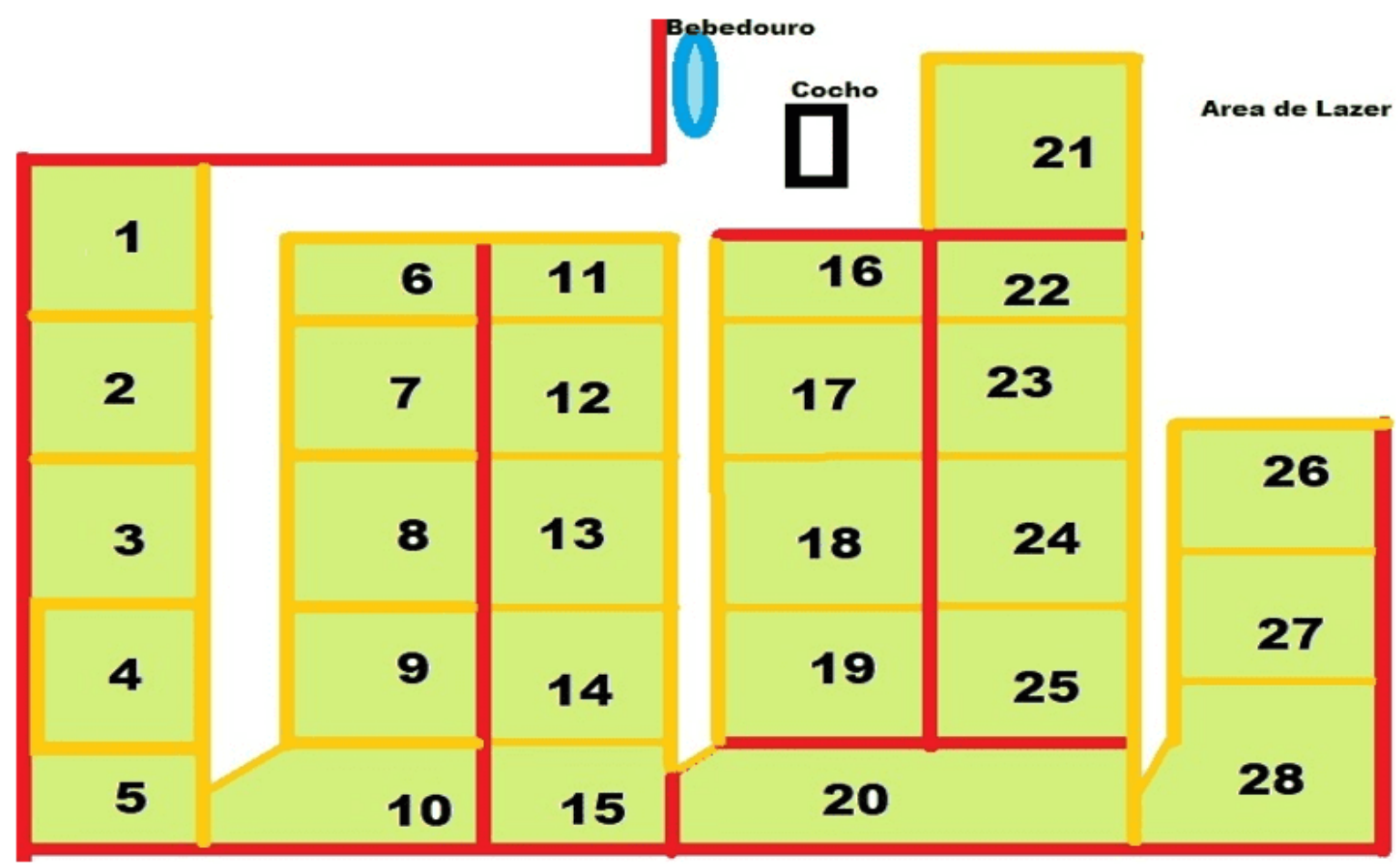

Fonte: Arquivo Pessoal.

A forrageira escolhida foi a Brachiaria Brizantha cv marandu, o manejo desta forrageira tem início quando a planta atinge $30 \mathrm{~cm}$ de entrada e $15 \mathrm{~cm}$ de saída Andrade (2008); Fonseca (2010). O plantio da forrageira e a adubação de plantio teve início no dia 15/11/2019, com a método de plantio a lanço e incorporação das sementes e do adubo fosfatado supersimples em seguida. As sementes eram incrustradas, sendo utilizado $15 \mathrm{~kg} \mathrm{ha}^{-1}$.

A primeira adubação de produção foi realizada 60 dias pós plantio, sendo aplicado $125 \mathrm{~kg} \mathrm{ha}^{-1}$ de ureia agrícola com $45 \%$ de nitrogênio. O primeiro pastejo teve início no dia 03/02/2020, 77 dias pós plantio. A segunda adubação de produção sendo aplicado $125 \mathrm{Kg} \mathrm{há}{ }^{-1}$ de ureia agrícola foi realizada ao primeiro ciclo de pastejo sendo 28 dias após o início do primeiro pastejo.

RC: 98111

Disponível em: https://www.nucleodoconhecimento.com.br/veterinaria/brachiariabrizantha 
Para o descanso dos animais foi adicionado um bebedor de água com aproximadamente $100 \mathrm{~L}$ de água, adição de sal mineral próprio para bovinos de leite e as próprias árvores da propriedade serviram de sombreamento.

Para realizar à análise econômica e avaliação do custo de produção de leite, identificou-se os agentes envolvidos, bem como os valores que representam os efeitos da implantação do projeto sobre esses agentes, considerando também o fechamento de um ano.

Para avaliar o custo de implantação do projeto considerou-se os custos de investimento no preparo solo e plantio da gramínea, bem como os investimentos para infraestrutura e equipamentos na formação dos piquetes.

Para avaliar o custo de produção, utilizou-se a estrutura do custo operacional de produção, proposta por Matsunaga (1976). Em que, o custo operacional efetivo (COE), corresponde ao dispêndio de dinheiro por parte do produtor, com compra de ração, gastos com a manutenção da pastagem e medicamentos, durante um ano.

Para o custo total de produção (CTP), foi adicionado ao (COE) a depreciação. A depreciação anual da pastagem foi calculada pelo somatório dos insumos necessários para a construção da cerca elétrica dividido pelo período de dez anos. Considerou-se uma depreciação de $10 \%$ ao ano (CANZIANI et al., 2000).

Para calcular a receita, considerou-se a receita líquida, que é o valor ganho na entrega de leite ao ano menos os custos totais de produção (MARTIN, 1997).

\section{RESULTADOS E DISCUSSÃO}

Dentro da produção agropecuária, é necessário ter um planejamento por parte do produtor, para que haja crescimento e desenvolvimento da atividade. Sendo assim, o primeiro passo para o estudo da viabilidade de um projeto, é fazer o levantamento de gastos para a implantação do mesmo. Os custos para a implantação desse 
projeto, desde a preparo do solo para o plantio da pastagem, até a formação dos piquetes foram de $\mathrm{R} \$ 3.023,70$.

Antes de realizar a implantação da gramínea $B$. brizantha cv. marandu, foi preciso fazer o preparo do solo. Os investimentos relacionados ao preparo do solo estão descritos na (Tabela 2).

Tabela 2 - Custos de investimento no preparo solo e plantio:

\begin{tabular}{|c|c|c|c|}
\hline Descrição & Unidade & Quantidade & Valor $(\mathrm{R} \$)$ \\
\hline Analises de Solo & Uni & 1 & 33,00 \\
\hline $\begin{array}{l}\text { Calcário dolomítico } \\
86 \%)\end{array}$ & $\mathrm{kg}$ & 800 & 156,00 \\
\hline Superfosfato (00.19.00) & $\mathrm{kg}$ & 250 & 287,46 \\
\hline Hora aração trator & $\mathrm{H}$ & 2 & 400,00 \\
\hline Semente incrustrada & $\mathrm{kg}$ & 15 & 287,01 \\
\hline Ureia Agrícola & $\mathrm{kg}$ & 250 & 400,00 \\
\hline Herbicida Glifosato & $\mathrm{mL}$ & 500 & 35,00 \\
\hline Óleo 2T & $\mathrm{mL}$ & 250 & 20,00 \\
\hline Combustível - Gasolina & $\mathrm{L}$ & 5 & 20,00 \\
\hline Total & & & $1.638,47$ \\
\hline
\end{tabular}

Fonte: Dados do Projeto.

Os custos com o preparo do solo e plantio, representaram $54,20 \%$ dos custos totais para implantação da pastagem. As práticas corretivas e a adubação do solo são apenas parte das exigências necessários para o sucesso do sistema de produção em pastagens (PEREIRA et al., 2018).

É importante o produtor investir e realizar um bom preparo de solo e uma correta implantação da pastagem, buscando sempre o equilíbrio no sistema solo-plantaanimal (PEREIRA et al., 2018). Esses manejos influenciarão no aumento da 
produção animal, bem como na diminuição dos gastos com ração para à alimentação dos animais.

$\mathrm{Na}$ busca de um manejo correto da pastagem, realizou-se a subdivisão da mesma em piquetes. Os investimentos para infraestrutura e equipamentos na formação dos piquetes estão representados na (Tabela 3).

Tabela 3 - Tabela de custo para formação dos piquetes, com a cerca elétrica:

\begin{tabular}{|l|l|l|l|}
\hline Descrição & Unidade & Quantidade & Valor (R\$) \\
\hline Arame eletrix & $\mathrm{m}$ & 500 & 184,00 \\
\hline Fio eletroplástico 500 m & $\mathrm{m}$ & 5 & 104,82 \\
\hline Isolador tipo castanha & Uni & 150 & 176,98 \\
\hline Isolador tipo vergalhão & Uni & 114 & 131,65 \\
\hline $\begin{array}{l}\text { Isolador tipo gancho } \\
\text { curto }\end{array}$ & Uni & 20 & 24,00 \\
\hline $\begin{array}{l}\text { Isolador tipo gancho } \\
\text { longo }\end{array}$ & Um & 2 & \\
\hline Chave interruptora & Um & 3 & 4,60 \\
\hline Vergalhão (3/8") 1.5 m & Um & 72 & 36,00 \\
\hline Vergalhão (1/2") 1.5 m & Um & 2 & 284,30 \\
\hline Tubo PVC 20 mm $6 \mathrm{~m}$ & Um & 1 & 186,18 \\
\hline Voltímetro digital & Um & 1 & 12,80 \\
\hline Eletrificador & Um & 1 & 139,90 \\
\hline Total & & & 100,00 \\
\hline
\end{tabular}

Fonte: Dados do Projeto.

Os custos com infraestrutura e equipamentos para formação dos piquetes representam $45,80 \%$ dos custos totais da implantação da pastagem. O manejo racional da forragem tem demonstrado amplamente os benefícios da divisão das pastagens, onde há uma maior uniformidade de pastejo, maior aproveitamento das

RC: 98111

Disponível em: https://www.nucleodoconhecimento.com.br/veterinaria/brachiariabrizantha 
forrageiras, maior taxa de lotação, e maior longevidade de capins que formam touceira (FUKUMOTO, 2010), que é o caso da B. brizantha cv. marandu. O uso da cerca elétrica, em suas diferentes formas no piqueteamento, é uma ferramenta necessária para que se possa implementar a baixo custo as subdivisões que o pastejo rotacionado requer (EMBRAPA, 1999).

Os bens que constituem 0 empreendimento estão sujeitos a constantes desvalorizações, devido, principalmente ao desgaste, e ao envelhecimento. A (Tabela 4) possui os dados de depreciação da cerca elétrica.

Tabela 4 - Depreciação dos materiais e equipamentos:

\begin{tabular}{|c|c|c|c|}
\hline Descrição & Valor total $\mathrm{R} \$$ & Vida útil (anos) & Valor anual \\
\hline $\begin{array}{l}\text { Construção da cerca } \\
\text { elétrica }\end{array}$ & $1.385,25$ & 10 & 138,52 \\
\hline
\end{tabular}

Fonte: Dados do Projeto.

Tabela 5 - Pagamento do investimento:

\begin{tabular}{|c|c|c|c|}
\hline Descrição & Valor total $\mathrm{R} \$$ & Tempo de pagamento (anos) & Valor anual \\
\hline $\begin{array}{ll}\text { Custo } & \text { de } \\
\text { implantação } & \end{array}$ & $3,023.70$ & 10 & 302.37 \\
\hline
\end{tabular}

Fonte: Dados do Projeto.

Para ter um maior controle anual sobre a gestão do negócio, os investimentos para a implantação foi divido em 10 anos. Sendo 4,20\% da receita anual da venda do leite, descritos na (tabela 5).

Para calcular a entrada monetária, em forma de dinheiro em um ano, foi considerado o valor pago ao produtor pelo litro de leite, vendido diariamente e direto do produtor forma durante um ano. Para calcular a quantidade de leite anual foi considera uma ordenha diária pela manhã com um total de 10 litros/dia (Tabela 6).

RC: 98111

Disponível em: https://www.nucleodoconhecimento.com.br/veterinaria/brachiariabrizantha 
Tabela 6 - Receita da venda do leite anual:

\begin{tabular}{|l|l|}
\hline Variáveis & Valor total \\
\hline Preço por litro $(\mathrm{R} \$)$ & 2,00 \\
\hline $\begin{array}{l}\text { Total de litros de leite produzido } \\
(\mathrm{L})\end{array}$ & $3.600,00$ \\
\hline Receita final $(\mathrm{R} \$)$ & $\mathbf{7 . 2 0 0 , 0 0}$ \\
\hline
\end{tabular}

Fonte: Dados do Projeto.

A cada ano o produtor terá que efetivar um dispêndio de dinheiro, sendo este considerado um Custo Operacional Efetivo (COE). Levou-se em consideração os custos com ração, gastos com a manutenção da pastagem e medicamentos (Tabela 7).

Tabela 7 - Custo Operacional Efetivo - COE, por ano:

\begin{tabular}{|l|l|l|l|l|}
\hline Descrição & Unidade & Quant & Valor unitário R\$ & Valor total R\$ \\
\hline Ração & $\mathrm{Kg}$ & 720 & 1,32 & 950,04 \\
\hline Ureia agrícola & $\mathrm{Kg}$ & 250 & 1,60 & 400,00 \\
\hline Energia elétrica & $\mathrm{R} \$$ & 12 & 0,60 & 216,00 \\
\hline Vacina brucelose & Dose & 6 & 1,62 & 9,72 \\
\hline Vacina raiva & Dose & 6 & 1,48 & 8,88 \\
\hline $\begin{array}{l}\text { Dectomax 50 mL } \\
\text { Vacina febre } \\
\text { aftosa }\end{array}$ & Dose & 1 & 21,90 & 21,90 \\
\hline Total & & & 1,50 & 9,00 \\
\hline
\end{tabular}

Fonte: Dados do Projeto.

Observa-se nesse trabalho que o maior gasto na produção é com ração. Segundo (MARTINEZ, 2009), o gasto com a nutrição representa em média $67 \%$ dos custos de produção de leite no Brasil. Desta forma, busca-se estratégias que visam reduzir o

RC: 98111

Disponível em: https://www.nucleodoconhecimento.com.br/veterinaria/brachiariabrizantha 
uso de rações e outros suplementos. Melhorar a pastagem e o manejo dela, é uma alternativa que ajuda a produção de leite ser economicamente viável. Por esse motivo o pastejo rotacionado vêm sendo cada vez mais indicado (MARION et al., 2010).

Rosestolato (2015), ao analisarem a viabilidade econômica da produção leiteira de duas propriedades distintas quanto ao sistema tecnológico de produção, observaram que o (COE) na propriedade em que as vacas eram mantidas em sistema de pastejo contínuo e suplementadas com ração concentrada e sal mineral foi maior do que da mantidas em sistema de pastejo rotacionado e suplementadas com cana picada, ração concentrada e sal mineral.

$\mathrm{Na}$ propriedade avaliada neste estudo, era dado $10 \mathrm{~kg}$ de ração industrializada por animal em lactação e após a implantação do projeto houve uma diminuição de $9 \mathrm{~kg}$ passando a oferecer apenas $1 \mathrm{~kg}$ de ração aos animais, diminuindo assim, o (COE), assim como observado por Rosestolato (2015). Contudo, a suplementação aos animais mesmo com a mudança no sistema de pastejo, é importante, uma vez que ajuda a suprir nos animais os nutrientes que faltam na composição da forragem. $O$ custo da ração representou $44,70 \%$ de todo custo de produção.

Considerando-se os valores de depreciação e custo operacional efetivo (COE), obteve-se o custo total de produção em um ano (Tabela 8).

Tabela 8 - Custo Total de Produção - CTP (Base anual):

\begin{tabular}{|l|l|}
\hline Descrição & Valor total R\$ \\
\hline Depreciação & 138,52 \\
\hline $\begin{array}{l}\text { Custos COE } \\
\text { Pagamento } \\
\text { investimento }\end{array}$ & $1.615,50$ \\
\hline Total & 302.37 \\
\hline
\end{tabular}

Fonte: Dados do Projeto.

RC: 98111

Disponível em: https://www.nucleodoconhecimento.com.br/veterinaria/brachiariabrizantha 
Nos países com baixos preços do leite, os produtores conseguem reduzir o custo de produção pelo aumento da participação do pasto na dieta das vacas leiteiras. Neste estudo o custo total de produção representou $28,55 \%$ da renda anual.

Para calcular a receita, considerou-se a receita líquida, que é o valor ganho na entrega de leite ao ano menos os custos totais de produção (Tabela 9).

Tabela 9 - Receita (Base anual):

\begin{tabular}{|l|l|}
\hline Descrição & Valor total $\mathrm{R} \$$ \\
\hline $\begin{array}{l}\text { Receita } \\
\text { Custo Total de Produção (CTP base } \\
\text { anual) }\end{array}$ & \begin{tabular}{l}
$7.200,00$ \\
\hline Saldo
\end{tabular} \\
\hline
\end{tabular}

Fonte: Dados do Projeto.

Segundo Oliveira (2007), o conhecimento das implicações do custo operacional efetivo (COE), em curto prazo, é fundamental na gestão do negócio, e a margem bruta precisa ser positiva, se for negativa, a interrupção da produção é recomendada.

A análise financeira de implantação deste projeto mostrou-se viável (Tabela 9). Diante das análises feitas a partir dos dados obtidos, observou-se que o investimento na técnica de pastejo rotacionado na pecuária leiteira apresenta um retorno economicamente viável do capital investido e que a mesma influência de forma positiva na produção tornando essa atividade mais competitiva no setor. Assim esta técnica permite a expressão potencial para produção de leite e o aumento da rentabilidade dos produtores, o que tornaria a atividade leiteira lucrativa, mesmo nos momentos de queda no preço do leite.

RC: 98111

Disponível em: https://www.nucleodoconhecimento.com.br/veterinaria/brachiariabrizantha 


\section{CONSIDERAÇÕES FINAIS}

De acordo com os resultados obtidos nas análises econômicas, conclui-se que a implantação do pastejo rotacionado e realização da troca da pastagem nativa pela Brachiaria brizantha cv. marandu, é um manejo viável, uma vez que as receitas geradas pela venda do leite, foram suficientes para cobrir os custos totais de produção.

Esse sistema semi-intensivo de produção é recomendado à realidade local, por ser uma alternativa de inovação tecnológica, capaz de diminuir os gastos com compra de ração, e proporcionar um bom desempenho animal, a partir da mudança do manejo de pastejo e inserção gramínea de melhor valor nutritivo e maior produção de massa.

\section{REFERÊNCIAS}

ANDRADE, Carlos Mauricio Soares de. Pastejo Rotacionado: Tecnologia para Aumentar a Produtividade de Leite e a Longevidade das Pastagens. EMBRAPA - Acre, dez. 2008.

ANUÁRIO LEITE 2019. Sua excelência, o consumidor: novos produtos e novas estratégias da cadeia do leite para ganhar competitividade e conquistar os clientes finais. Brasília, DF: Texto Comunicação Corporativa, 2019. Disponível em: $<$ https://www.infoteca.cnptia.embrapa.br/infoteca/handle/doc/1109959>. Acesso em: 25 mar. 2020.

DEMSKI, Joana Baptista. Desempenho e comportamento de vacas lactantes em pastagens de cultivares de braquiárias. Dissertação apresentada ao Programa de Pós-graduação do Instituto de Zootecnia, APTA/SAA. Nova Odessa - SP, 2013. $80 \mathrm{p}$.

FONSECA, Delermando Miranda da; MARTUSCELLO, Janaina Azevedo. Plantas forrageiras. Viçosa, 537p. 2010.

RC: 98111

Disponível em: https://www.nucleodoconhecimento.com.br/veterinaria/brachiariabrizantha 
FUKUMOTO, Nelson Massaru; DAMASCENO, Júlio Cesar; DERESZ, Fermino, MARTINS, Carlos Eugênio; CÓSER, Antônio Carlos; SANTOS, Geraldo Tadeu dos. Produção e composição do leite, consumo de matéria seca e taxa de lotação em pastagens de gramíneas tropicais manejadas sob lotação rotacionada. Revista Brasileira de Zootecnia, v. 39, n.7, p. 1548-1557, 2010.

GERON, Luiz Juliano Valério; MEXIA, Alexandre Agostinho; GARCIA Jocilaine; SILVA Marciano Moreira da; ZEOULA, Lúcia Maria. Suplementação concentrada para cordeiros terminados a pasto sobre custo de produção no período da seca. Semina: Ciências Agrárias, Londrina, v. 33, p. 797-808, 2012.

GERON, Luiz Juliano Valério; MOURA, Daiane Caroline; RODRIGUES, Deivison Novaes; PAULA, Edson Júnior Heitor; TRAUTMANN-MACHADO, Raquel Joana; GARCIA, Jocilaine; SCHUMANN, Alline Mariá; SILVA; Dilma Alves. Viabilidade econômica de tourinhos terminados em confinamento alimentados com diferentes teores de caroço de algodão em dietas elaboradas com coprodutos agroindustriais. Semina: Ciências Agrárias, Londrina, v.35, p. 2673-2684, 2014.

GONÇALVES, Carlos Alberto; CAMARÃO, Ari Pinheiro; DUTRA, Saturnino; AZEVEDO, Guilherme Pantoja Calandrini de; MENDONÇA, Denise Castro; SOBRINHO, Carlos de Melo Junior. Produção de leite em pastejo rotacionado intensivo de "Brachiaria brizantha" cv. Marandu sob dois níveis de suplementação concentrado. In: Reunião anual da sociedade brasileira de zootecnia, 40., 2003, Santa Maria. Anais... Santa Maria: Sociedade Brasileira de Zootecnia, 2003.

IBGE -Instituto Brasileiro de Geografia e Estatística. [2018]. Pesquisa da pecuária nacional disponível em: <https://sidra.ibge.gov.br/Tabela/74>. Acessado em: 25 mar. 2020.

IPARDES: Instituto Paranaense de Desenvolvimento Econômico e Social. Caracterização sócio econômica da atividade leiteira no Paraná: Sumário executivo. Curitiba: IPARDES, 2009. 29 p.

RC: 98111

Disponível em: https://www.nucleodoconhecimento.com.br/veterinaria/brachiariabrizantha 
JANK, Liana; ANDRADE, Carlos Mauricio Soares de; BARBOSA, Rodrigo Amorim; MACEDO, Manuel Claudio Motta; VALERIO, Jose Raul; VERZIGNASSI, Jaqueline Rosemeire; ZIMMER, Ademir Hugo; FERNANDES, Celso Dornelas; SANTOS, Mateus Figueiredo; RESENDE, Rosangela Maria Simeão. O capim-BRS Quênia (Panicum maximum Jacq.) na diversificação e intensificação das pastagens. Disponível em: $<$ https://ainfo.cnptia.embrapa.br/digital/bitstream/item/165106/1/Capim-BRS-QueniaPanicum-maximum-Jacq.pdf>. Acesso em: 25 mar. 2020.

MARION, Jose Carlos; SEGATTI, Sonia. Contabilidade da Pecuária. 9 ed. São Paulo: Atlas, 2010.

MARTIN, Nelson Batista; SERRA, Renata; OLIVEIRA, Marli Dias Mascarenhas; ÂNGELO, José Alberto; OKAWA, Hiroshige. Sistema "CUSTAGRI": sistema integrado de custos agropecuários. São Paulo: IEA/SAA, 1997. p. 1-75.

MARTINEZ, Junior Cesar. Produção de leite a pasto: manejo do pastejo é fundamental para manter a produção. 2009. Disponível em: <http://www.milkpoint.com.br/radartecnico/nutricao/producao-deleite-a-pasto-manejodo-pastejo-e-fundamental-para-manter-aproducao-51710n.aspx>. Acesso em: 27 mai. 2020.

MATSUNAGA, Minoru; BEMELMANS, Paul Frans; TOLEDO, Paulo Edgard Nascimento de; DULLEY, Richard Domingues; HIROSHIGE, Okawa; PEDROSO, Iby Arvatti. Metodologia de custo utilizada pelo IEA. Agricultura em São Paulo, v. 23, n. 1, p.123-39, 1976.

OLIVEIRA, Jefferson Soares de. Análise de eficiência e alocação de recursos na produção leiteira do estado do Rio de Janeiro. In: congresso da sociedade brasileira de economia, administração e sociologia rural, 45., 2007. Londrina. Conhecimentos para a agricultura do futuro: Anais... Brasília, DF: SOBER; Londrina: IAPAR: Universidade Estadual de Londrina, 2007.

RC: 98111

Disponível em: https://www.nucleodoconhecimento.com.br/veterinaria/brachiariabrizantha 
PEREIRA, Lilian Elgalise Techio. et al. Recomendações para correção e adubação de pastagens tropicais. Pirassununga: Faculdade de Zootecnia e Engenharia de Alimentos da USP, 2018. 56p.

ROSESTOLATO, Lucas Luiz Rocha. et al. Viabilidade econômica comparativa de sistemas tecnológicos da pecuária leiteira no município de llha Solteira/SP. Congresso de extensão universitária da UNESP, 8., p. 1-6, 2015. Disponível em: <http://hdl.handle.net/11449/142491>. Acesso em: 28 mai. de 2020.

SEAB - Secretaria de Estado da Agricultura e do Abastecimento. Bovinocultura de leite: leite - $\quad$ produção $2016 / 17 . \quad$ Disponível em:<http://www.agricultura.pr.gov.br/arquivos/File/deral/Prognosticos/2018/leite_201 7_18.pdf>. Acesso em: 25 mar. de 2020.

Enviado: Julho, 2021.

Aprovado: Setembro, 2021. 